\title{
Influence of surface-modified montmorillonites on properties of silicone rubber-based ceramizable composites
}

\author{
R. Anyszka • D. M. Bieliński $\cdot$ Z. Pędzich • \\ M. Szumera
}

Received: 16 December 2013/Accepted: 29 August 2014/Published online: 12 September 2014

(c) The Author(s) 2014. This article is published with open access at Springerlink.com

\begin{abstract}
Ceramizable (ceramifiable) silicone rubberbased composites are modern elastomeric materials for fire protection application. The most important sector of economy using such materials is cable industry because there are special types of electric circuits that have to keep working in the case of fire. These kinds of composites can create ceramic phase protecting copper wire from melting under high temperature. When temperature increases, polymer matrix degrades (creating silica residue as one of the products) and mineral particles dispersed in silicone rubber matrix stick together creating stiff, durable, insulating and porous ceramic skin. In this paper, the influence of surface modification of montmorillonite with quaternary ammonium salts on ceramization of their silicone rubber composites is presented. Filler modification was studied, determining changes to its surface energy and thermal stability. Mechanical properties, flammability and thermal stability of composites were determined. Ceramization of
\end{abstract}

R. Anyszka ( $\square)$ · D. M. Bieliński

Faculty of Chemistry, Institute of Polymer \& Dye Technology, Lodz University of Technology, Stefanowskiego 12/16, 90-924 Łódź, Poland

e-mail: 800000@edu.p.lodz.pl

D. M. Bieliński

e-mail: dariusz.bielinski@p.lodz.pl

D. M. Bieliński

Division of Elastomers \& Rubber Technology, Institute for Engineering of Polymer Materials \& Dyes, Harcerska 30, 05-820 Piastów, Poland

\section{Z. Pędzich · M. Szumera}

Department of Ceramics and Refractory Materials, Faculty of Materials Science \& Ceramics, AGH - University of Science \& Technology, Al. Mickiewicza 30, 30-045 Kraków, Poland e-mail: pedzich@agh.edu.pl the composites was discussed from the point of view of their mechanical properties and structure of ceramic phase after heat treatment, determined by compression stress tests, porosimetry and scanning electron microscopy adequately. Results show that type of modifier applied strongly affects properties of silicone rubber-based ceramizable composites before and after ceramization. Samples containing surface-modified montmorillonite produce significantly less heat during their thermal decomposition than composite filled with unmodified montmorillonite. Moreover, incorporation of montmorillonite modified with ammonium salt of linear organic chain causes the creation of nano-porous structure after ceramization. On the one hand, it facilitates heat insulation, but on the other hand, high total volume of pores adversely affects mechanical endurance of the ceramic phase.

Keywords Polymer composites - Ceramization Ceramification - Thermal properties · Organophilized montmorillonites

\section{Introduction}

Ceramization (ceramification) is a process developed for fire protecting polymer application based on the creation of stiff, durable and porous ceramic structure as a result of exposing material to elevated temperature and/or fire. This ceramic, cellular barrier can: (1) block propagation of flames and (2) prevent oxygen from deeper penetrating of burning material and production of flammable, caloric fuel during thermal destruction of polymer matrix. It also creates a barrier to heat propagation so as to protect copper wire from melting. Ceramization effect is based on sticking mineral particles dispersed in polymer matrix together in 
Fig. 1 Sintering mineral particles during heat treatment, diagram proposed by Xiong et al. [14]

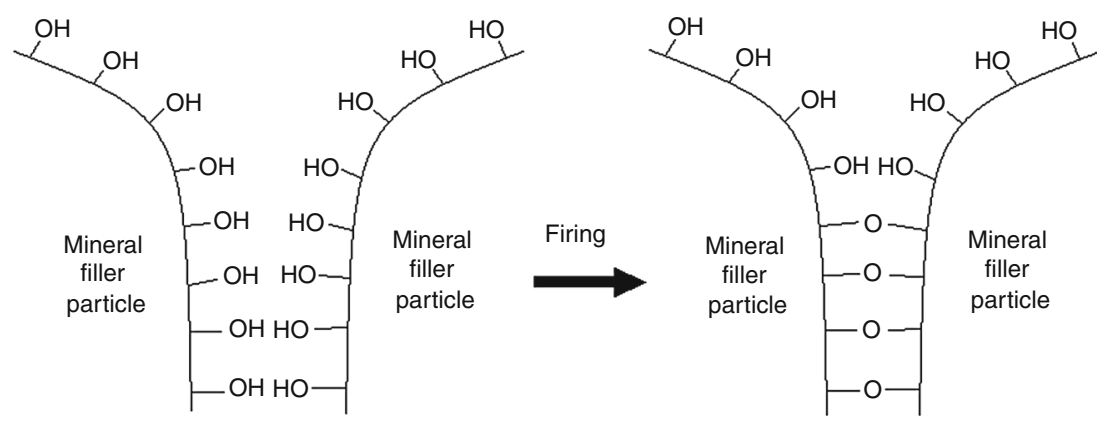

different processes, generally in the presence of fluxing agent [1-8]. Even without the addition of inorganic filler of relatively low softening point temperature (fluxing agent like glass oxide frits), the effect of fire char formation can be observed, but its durability and shape preservation leave much to be desired, especially when ceramization occurs at quite low temperature $\left(550-800{ }^{\circ} \mathrm{C}\right)$ [9-15]. Polymer materials (especially based on fully organic thermoplastics or elastomers) exposed to fire undergo strong thermal degradation and destruction [16-21] very often accompanied by the effect of burning drops, which can significantly increase the spread of flames [22]. Therefore, a lot of flame retardant systems preventing this phenomenon have been developed in the past few years [23].

Chemical mechanism of flame retardancy is based on free radicals deactivation slowing down the increase of combustion process. But those systems usually require the addition of chemical reagents containing components, which produce harmful or toxic products (compounds containing halides, nitrogen or phosphorus) during thermal destruction. Therefore, they are gradually eliminated from practice. On the other hand, non-toxic flame retardants, such as aluminum hydroxide or montmorillonite, are less effective in the case of fire when they are used alone. For this reason, ceramization process was developed as the next step in physical methods of fire protection.

This idea was utilized for the first time in cable industry where silicone rubber-based ceramizable composites are aimed to protect copper wire in cables from fire melting. The composites exposed to flames and elevated temperature create ceramic phase protecting wire and ensure electric integration of the circuit up to $120 \mathrm{~min}$. The family of these materials is still increasing, being the result of more and more research devoted to this issue [1-9, 11-14].

As it was mentioned before, ceramization can occur only in the presence of mineral fillers which may be sintered at elevated temperature (Fig. 1). This process is improved in the case of silicone rubber-based composites, where silica particles created after thermal destruction of polymer $[24,25]$ can additionally connect the primary mineral particles together (Fig. 2). Moreover, the polysiloxanes, especially the most popular polydimethylsiloxane (PDMS), have very good thermal stability (they can maintain their properties even up to $400{ }^{\circ} \mathrm{C}$ ) because of the presence $\mathrm{Si}-\mathrm{O}$ backbone in their chains, which makes them the best polymeric family for manufacturing ceramizable composites.

Montmorillonite (MMT) is a layered silicate mineral with a well-defined structure [26], where sheets of aluminum silicates are separated by loosely bonded metal cations (generally sodium or calcium). Depending on the type of montmorillonite, the distance between aluminosilicate galleries can vary from 1.0 to $2.1 \mathrm{~nm}$ (Fig. 3). Cations present in these gaps can be easily exchanged to organic compounds such as quaternary ammonium cations facilitating organofilization of filler surface and increase its affinity toward polymer matrix (Fig. 4). As a result of this process, it is possible to achieve a very good dispersion of layered mineral in silicone composites and transform its structure from intercalated to a delaminated one (Fig. 5). Zhang et al. proved that the application of organically modified montmorillonite as a filler in polymer composites may lead to obtain cellular protective structure of residue after burning or heating the material [15]. Quaternary ammonium treatment of montmorillonite surface is thermally unstable above $200{ }^{\circ} \mathrm{C}$. Organic cations desorb and decompose during heat increasing via Hoffman elimination reaction $[10,27]$. In this reaction, beta hydrogen in the alkyl group is eliminated with the creation of alpha olefin and free amine. The proton of beta-elimination reaction remains on the surface of the montmorillonite sheet, giving acidic clay site. This active surface can catalyze the following reactions of polymer decomposition and char formation of material under fire [28, 29]. Moreover, volatiles created in Hoffman elimination can induce the creation of microporous structure during ceramization process.

Commercially available organofilized montmorillonites are quite new type of fillers. Their gallery structure allows to perform an effective modification of monolayers by cations, for example, originated from quaternary ammonium salts. In this way, the chemical interaction between polymer and filler increases, leading to better dispersion of filler in polymer matrix, which can improve the properties of ceramic phase obtained after ceramization. Nowadays, a large number of organofilized mineral powders are 
Fig. 2 Sintering mineral SR - silicone rubber particles during heat treatment in the presence of silicone rubber macromolecules, diagram proposed by Xiong et al. [14]

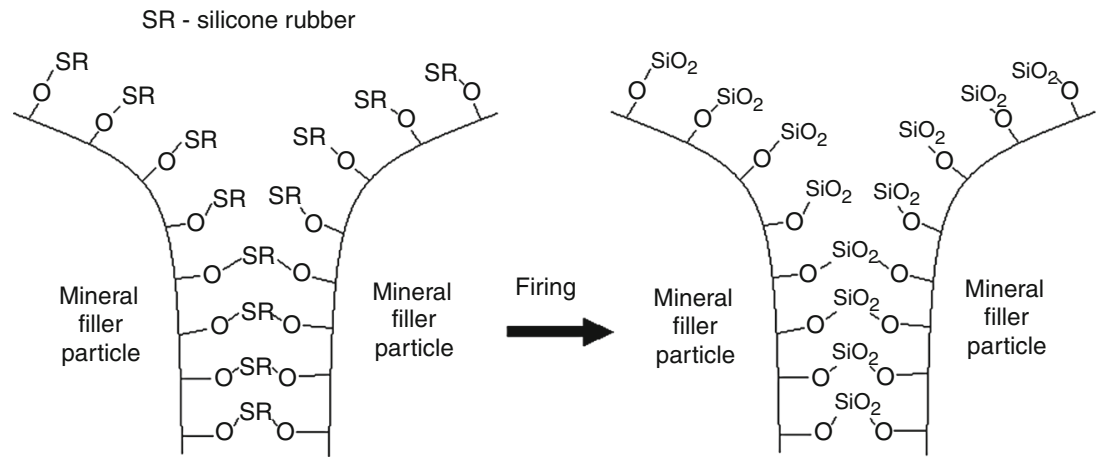

\begin{tabular}{c}
\hline Aluminosilicate sheet \\
Cations and water \\
Aluminosilicate sheet
\end{tabular}

Fig. 3 Montmorillonite structure [22]

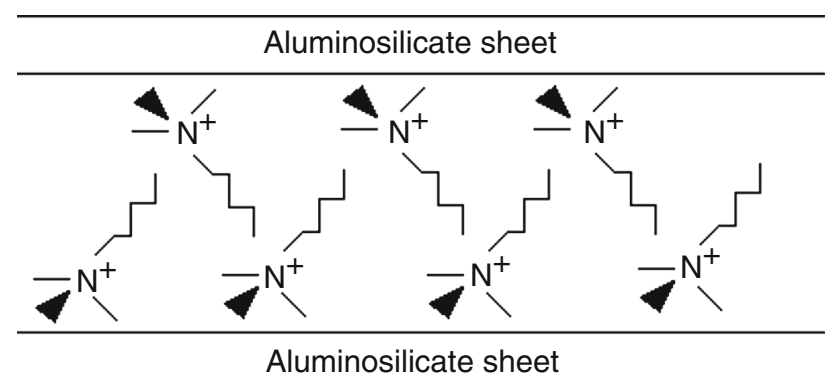

Fig. 4 Scheme of surface modification of montmorillonite sheet using quaternary ammonium cations available, making it possible to compound novel types of composites of improved or unique properties.

In this paper, the influence of surface-modified montmorillonites on the properties of ceramizable silicone rubber composites was studied.

\section{Experimental}

\section{Materials}

Silicone elastomer (HTV) containing $0.07 \%$ of vinyl groups produced by "Polish Silicones" Ltd., reinforced by "Aerosil 200" (Evonik Industries) fumed silica, was used as a base. As a fluxing agent we used boron oxide from "Sigma Aldrich" company. Titanium and magnesium oxides were used as refractory fillers, enhancing ceramization process. To modify ceramization process of the base composites organo-modified montmorillonites (OMMT) (Fig. 6): Cloisite 11B, Cloisite 20A and Cloisite 93A, produced by "Rockwood Additives," were admixed. For the reference, samples containing non-modified (Dellite HPS) and modified by methyltributylammonium chloride $75 \%$ aqueous solution (Sigma Aldrich) MMT were also prepared (Fig. 7).
Fig. 5 Scheme of intercalated and delaminated structures of MMT-polymer composites

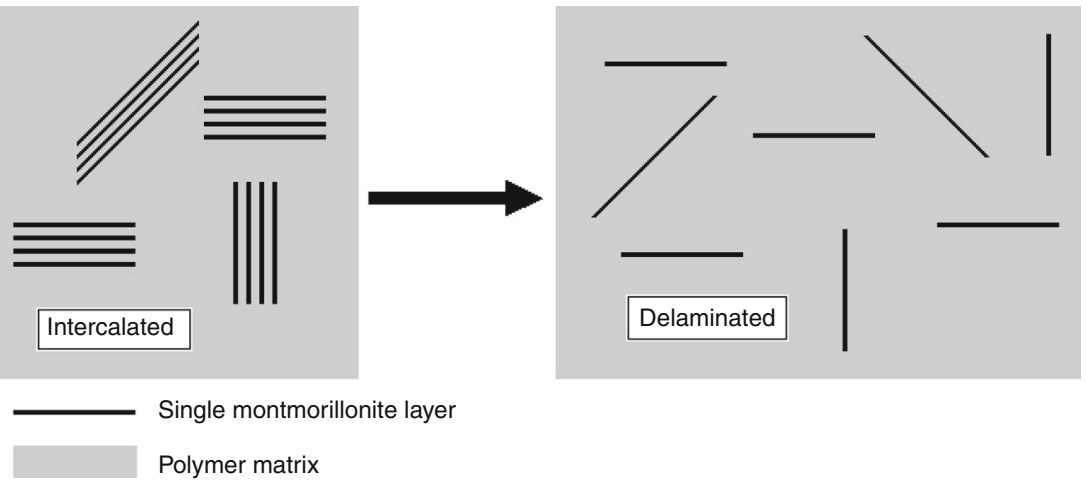


<smiles>C[N+](C)(C)Cc1ccccc1</smiles>

Cloisite 11B<smiles>CC[N+](C)(C)[In]</smiles>

Cloisite 20A<smiles>C[NH+]([In])[IH]</smiles>

Cloisite 93A
Fig. 6 Types of cations used in intercalated commercially available montmorillonites, where " $\mathrm{T}$ " is tallow-mixture containing hydrocarbons- $65 \%$ of $\mathrm{C} 18,30 \%$ of $\mathrm{C} 16$ and $5 \%$ of $\mathrm{C} 14$

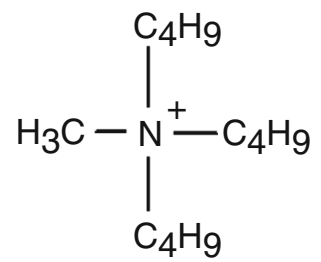

Fig. 7 Methyltributylammonium cation used to modify the surface of montmorillonite in the laboratory treatment

\section{Modification of montmorillonite surface}

To modify the surface of MMT powder (Dellite HPS), we used methyltributylammonium chloride $75 \%$ aqueous solution. First, MMT was added to $19 \% \mathrm{H}_{2} \mathrm{SO}_{4}$ aq solution and stirred during $3 \mathrm{~h}$ in order to activate montmorillonite galleries and remove present cations. Then, the powder was washed with distilled water and placed in methyltributylammonium chloride solution containing $7.5 \mathrm{~g}$ of methyltributylammonium chloride salt on $100 \mathrm{~g}$ of MMT. Next, the suspension was stirred during another $3 \mathrm{~h}$. After that, we washed modified powder with distilled water and let it dry at $120^{\circ} \mathrm{C}$ for another $12 \mathrm{~h}$.

Preparation of the samples studied

Silicone rubber-based mixes (Table 1) were prepared with a Brabender-Plasticorder laboratory mixer (Germany), whose rotors were operating with $20 \mathrm{rmin}^{-1}$ during components incorporating $(5 \mathrm{~min})$ and $60 \mathrm{r} \mathrm{min}^{-1}$ during their homogenization $(10 \mathrm{~min})$. Samples were vulcanized using laboratory electrically heated press, in steel moulds, at $130{ }^{\circ} \mathrm{C}$, during $15 \mathrm{~min}$.

\section{Techniques}

Thermal stability of modified and unmodified MMT samples was studied using a Netzsch TG 209 (Germany) TGA
Table 1 Composition of the silicone rubber mixes studied [parts per hundred parts of rubber (phr)]

\begin{tabular}{|c|c|c|c|c|c|}
\hline \multirow[t]{2}{*}{ Component } & \multicolumn{5}{|l|}{ Sample } \\
\hline & CL11B & CL20A & CL93A & DEL & $\begin{array}{l}\text { DEL- } \\
\mathrm{M}\end{array}$ \\
\hline Silicone rubber & 100 & 100 & 100 & 100 & 100 \\
\hline Fumed silica & 50 & 50 & 50 & 50 & 50 \\
\hline Fluxing agent $\left(\mathrm{B}_{2} \mathrm{O}_{3}\right)$ & 15 & 15 & 15 & 15 & 15 \\
\hline $\mathrm{TiO}_{2}$ & 5 & 5 & 5 & 5 & 5 \\
\hline $\mathrm{MgO}$ & 2 & 2 & 2 & 2 & 2 \\
\hline Cloisite 11B & 10 & - & - & - & - \\
\hline Cloisite 20A & - & 10 & - & - & - \\
\hline Cloisite 93A & - & - & 10 & - & - \\
\hline Dellite HPS & - & - & - & 10 & - \\
\hline $\begin{array}{l}\text { Dellite HPS modified in } \\
\text { laboratory }\end{array}$ & - & - & - & - & 10 \\
\hline $\begin{array}{l}\text { 2,4-Dichlorobenzoyl } \\
\text { peroxide (50 \% paste) }\end{array}$ & 1.25 & 1.25 & 1.25 & 1.25 & 1.25 \\
\hline
\end{tabular}

instrument. Montmorillonites were heated from ambient temperature to $500{ }^{\circ} \mathrm{C}$ at the heating rate of $10{ }^{\circ} \mathrm{C} \mathrm{min}-1$. Thermal stability of the composites was determined using a Netzsch STA 449F3 Jupiter (Germany) TG-DTA device. All the samples were heated from ambient temperature to $1,000{ }^{\circ} \mathrm{C}$ at the heating rate of $10{ }^{\circ} \mathrm{C} \mathrm{min}^{-1}$. Flammability of composites was studied by oxygen index (OI) determination, according to ISO 4589 standard using a homemade apparatus.

Surface energy of fillers was determined using a Kruss $\mathrm{K}-100$ tensiometer (Germany) measuring sorption of n-heptane, toluene, ethanol and methanol.

Mechanical properties of the composites: elongation at break (Eb), mechanical moduli at 100, 200 and $300 \%$ of elongation (SE100, SE200 and SE300) and tensile strength (TS) were measured using Zwick-Roell 1435 instrument (Germany).

Samples were ceramized in a laboratory furnace by heating from ambient temperature to $1,000{ }^{\circ} \mathrm{C}$ during $2 \mathrm{~h}$ (heating rate $\sim 8{ }^{\circ} \mathrm{C} \mathrm{min}^{-1}$ ). Then, they were cooled down in open air and immediately tested for porosity, using a mercury porosimeter Carlo Erba 2000 (Italy) and mechanical strength under compression using a Zwick Roell Z 2.5 tester (Germany). Average values of maximal force required to crush ceramic phase were calculated from 5 samples measurements. For complementary microstructure analysis of the ceramized composite samples, scanning electron microscopy pictures of their morphology were taken using a Nova Nano SEM 200 FEI (UK) instrument. 
Fig. 8 Thermogravimetric analysis of the fillers studied

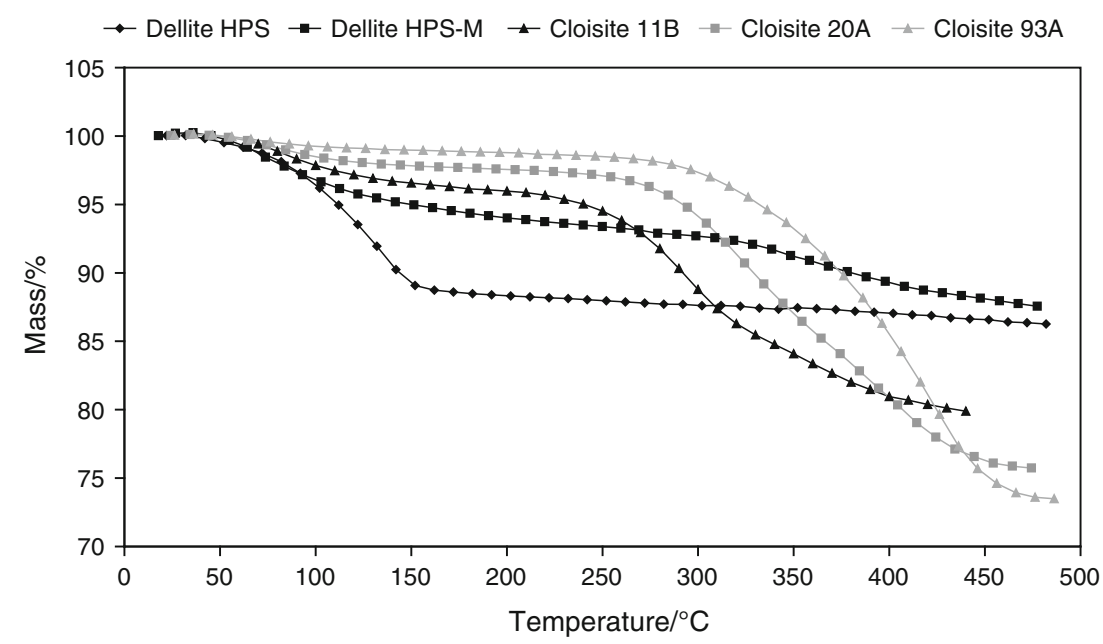

Table 2 Surface energy of the fillers studied $\left(\mathrm{mN} \mathrm{m}^{-1}\right)$

\begin{tabular}{lccccc}
\hline & $\begin{array}{l}\text { Dellite } \\
\text { HPS }\end{array}$ & $\begin{array}{l}\text { Dellite } \\
\text { HPS-M }\end{array}$ & $\begin{array}{l}\text { Cloisite } \\
11 \mathrm{~B}\end{array}$ & $\begin{array}{l}\text { Cloisite } \\
\text { 20A }\end{array}$ & $\begin{array}{l}\text { Cloisite } \\
\text { 93A }\end{array}$ \\
\hline $\begin{array}{l}\text { Polar } \\
\text { component }\end{array}$ & 3.1 & 3.9 & 0.0 & 0.9 & 4.6 \\
$\begin{array}{c}\text { Dispersion } \\
\text { component }\end{array}$ & 22.5 & 25.1 & 14.9 & 14.7 & 14.2 \\
$\begin{array}{c}\text { Summary } \\
\text { Summary }\end{array}$ & 25.6 & 29.0 & 14.9 & 15.6 & 18.8 \\
\hline
\end{tabular}

\section{Results and discussion}

Characterization of fillers

Using thermogravimetry made it possible to determine the amount of organic part and volatiles present in the filler samples studied (Fig. 8).

Surprisingly, unmodified MMT (Dellite HPS) contained large amounts of volatiles, almost 15 mass \%. Characteristic sharp drop of mass in temperature range $100-150{ }^{\circ} \mathrm{C}$ amount of water is responsible for the mass drop. But later on the mass is still slightly decreasing, which can be associated with some organic impurities present in unmodified MMT samples. Commercial-type powders contain much more organic components, from $20 \%$ (Cloisite 11B) to even over 25 mass \% (Cloisite 93A). MMT modified in our laboratory, using quaternary ammonium salt, exhibited the lowest mass loss. In its case water was replaced by a short-chain organic component.

After laboratory treatment, surface energy of modified MMT was increased and showed to be the highest within all the fillers studied (Table 2). Both polar and dispersion components are higher than in the case of non-treated powder. The lowest value of surface energy was obtained for Cloisite 11B (no polar component), whereas the highest polar component was determined for Cloisite 93A MMT.
Table 3 Mechanical moduli at $100 \%$ (SE100), $200 \%$ (SE200) and $300 \%$ (SE300) of elongation, tensile strength (TS), elongation at break $(\mathrm{Eb})$ and oxygen index value (OI) of the composites studied

\begin{tabular}{llllll}
\hline & DEL & DEL-M & CL93A & CL20A & CL11B \\
\hline SE100/MPa & 0.8 & 1.1 & 1.2 & 0.7 & 0.8 \\
SE200/MPa & 1.0 & 1.5 & 1.5 & 0.8 & 0.9 \\
SE300/MPa & 1.4 & 2.1 & 2.0 & 1.0 & 1.1 \\
TS/MPa & 3.3 & 3.6 & 3.4 & 2.1 & 2.0 \\
Eb/\% & 662 & 536 & 561 & 828 & 694 \\
OI/\% & $>37.5$ & $>37.5$ & $>37.5$ & $>37.5$ & 37.5 \\
\hline
\end{tabular}

Surface energy of Dellite HPS was increased after modification; both its polar and dispersion components are higher for a modified filler than for an unmodified one. Probably, the amount of methyltributylammonium cations was too low to cover the whole specific surface of MMT powder, so surface energy was higher because of the acid pre-treatment. Surprisingly, high value of polar component was determined for Cloisite 93A filler, probably because it contains the highest amount of organofilizer.

Properties of the composites

Elongation at break (Eb) as well as mechanical moduli (SE), tensile strength (TS) and oxygen index value (OI) of the composites studied are presented in Table 3.

Elongation at break reflects the elastic properties of rubber composites, and its value is quite important from the point of view of their application. The addition of Cloisite $20 \mathrm{~A}$ montmorillonite to the silicone rubber base results in the highest elongation at break value (over $800 \%$ ) among the materials studied. Composites containing Cloisite $93 \mathrm{~A}$ and MMT modified in our laboratory are the least elastic.

Type of montmorillonite filler strongly affects the mechanical properties of the composites studied. The least 
Fig. 9 DSC analysis of samples studied

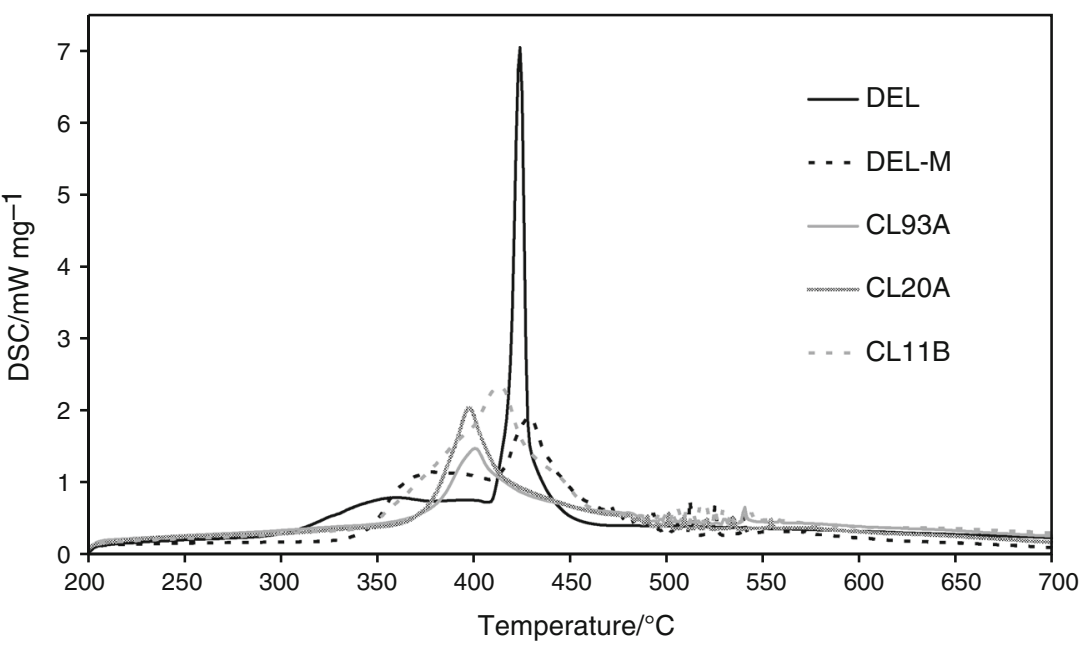

elastic samples (DEL-M, CL93A) exhibit the highest mechanical strength, whereas the weakest composite is the one containing Cloisite 11B filler (CL11B). Probably, the value of the polar component of surface energy of fillers influences interaction between reinforcing filler particles, providing to obtain stronger secondary structure. Also, the summary value of fillers surface energy may be responsible for enhancing the mechanical properties of the composites. From this point of view, it appears that interactions between filler particles can be more important for increasing tensile strength of silicone composites than other factors, such as polymer-filler interaction (polydimethylsiloxane does not have any polar groups) or possibility of creation covalent bonds between silicone matrix and organofilizer molecules. This situation cannot occur in the case of DEL sample, containing unmodified montmorillonite. Moreover, the possibility of creation of this type of bonds is the highest for samples filled with commercially available powders from Cloisite family, because of the highest amount of organic modifier present in their structure. Despite this, only CL93A sample presents good mechanical properties. All samples are highly nonflammable; oxygen index value for almost all of them is higher than $37.5 \%$, which is the limit available for the instrument used. OI value equal to $37.5 \%$ was obtained only for CL11B composite, probably because Cloisite 11B presents the least thermal stability among all commercial fillers studied (Fig. 8). Organic volatiles emitted during thermal degradation of this filler act as a fuel in burning process.

Results obtained from DSC analysis demonstrate that addition of surface-modified montmorillonite makes heat emission intensity during thermal decomposition of composites decreased significantly (Fig. 9). Mass changes of samples during TG test were very similar under $400{ }^{\circ} \mathrm{C}$, but finally samples containing commercially available modified montmorillonite exhibit worse thermal stability than DEL and DEL-M composites. Amount of residue after thermal decomposition of the samples differs visibly (Fig. 10). It seems interesting that sample CL11B creates more residue than sample DEL, being filled with unmodified montmorillonite. Probably, high amount of water in unmodified montmorillonite enhances the degradation of silicone matrix due to externally catalyzed mechanism and leads to the creation of volatile cyclosiloxanes [9]. The lowest value of residue presents CL93 sample containing montmorillonite with the highest amount of modifier, whereas the highest value of residue presents DEL-M sample containing filler with the lowest amount of modifier.

Properties of ceramic phase after heat treatment

Porosity analysis of the ceramic phase created after heat treatment of the composites studied is presented in the form of cumulative and distributive curves in Figs. 11 and 12.

Pore analysis of ceramic phases created after heat treatment shows that the composite filled with montmorillonite modified by quaternary ammonium salt of short organic chains (DEL$\mathrm{M})$ can produce nano-porous structure of high nano-porous content. Probably, the volatiles created during thermal degradation of organofilized MMT with short organic chains provide forming of nano-pores, according to Hoffman elimination reaction. This effect can enhance the insulating properties of ceramic shield, which, together with improved mechanical strength, represented by nano-porous ceramic, results in better protection of copper wire in the case of fire.

In the case of the ceramized materials containing commercially available organo-modified montmorillonites, only two of them can create nano-pores (CL93A and CL20A). Their amount, however, is lower in comparison with DEL-M sample. Moreover, total volume of micro-size pores is clearly higher in their cases than in the case of 
Fig. 10 TG analysis of samples studied

Fig. 11 Cumulative (a) and derivative (b) pore size analysis for the ceramized composites containing non-modified (DEL) and laboratory-modified (DELM) montmorillonites
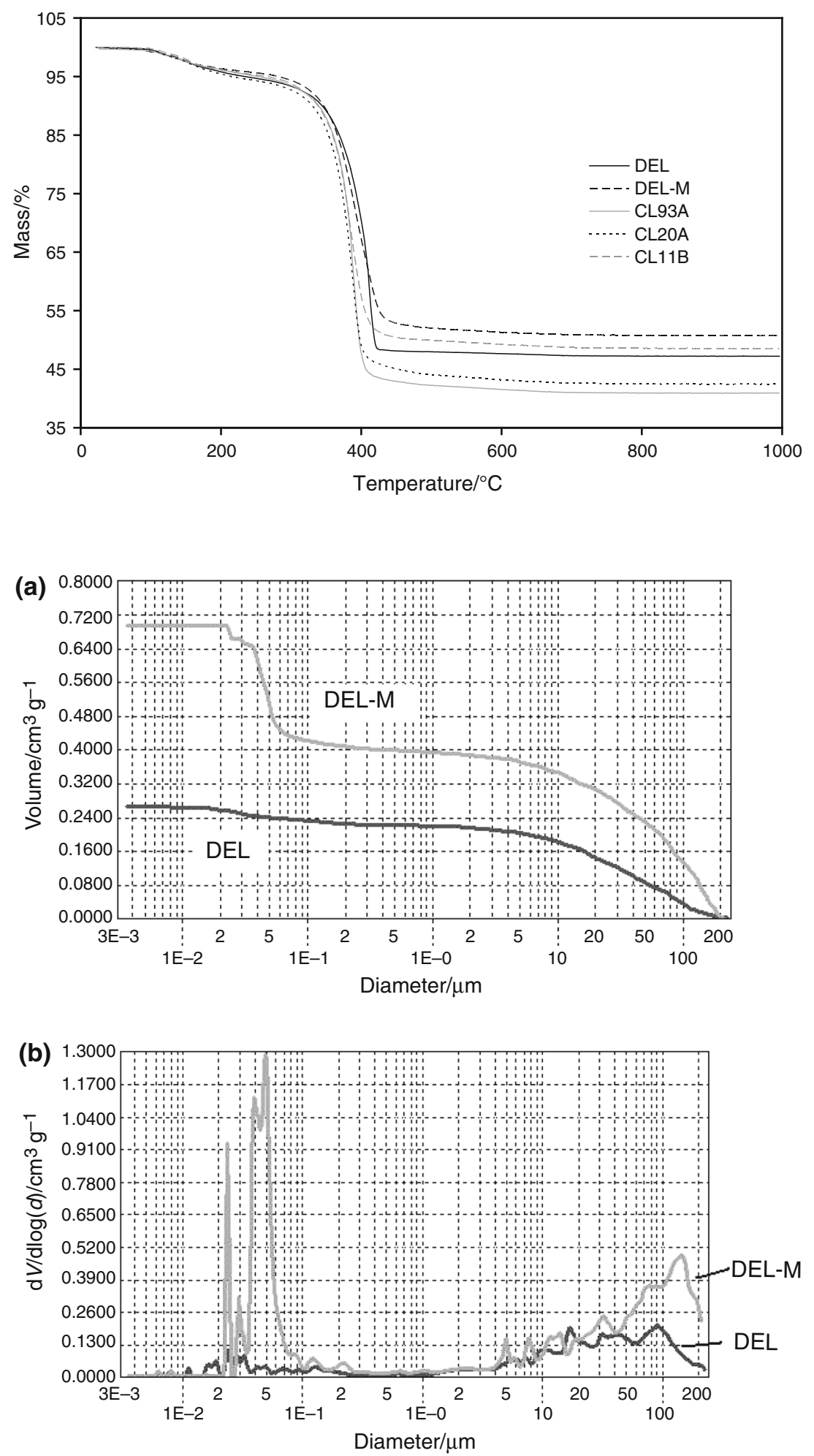

previous samples, which can negatively affect the mechanical properties of ceramic coating created in ceramization process.
Mechanical strength of ceramized samples was characterized as a maximal value of force required to destroy them under compression test (Table 4). 
Fig. 12 Cumulative (a) and derivative (b) pore size analysis for the ceramized composites containing commercially available surface-modified montmorillonites (Cloisite 11B, 20A and 93A)
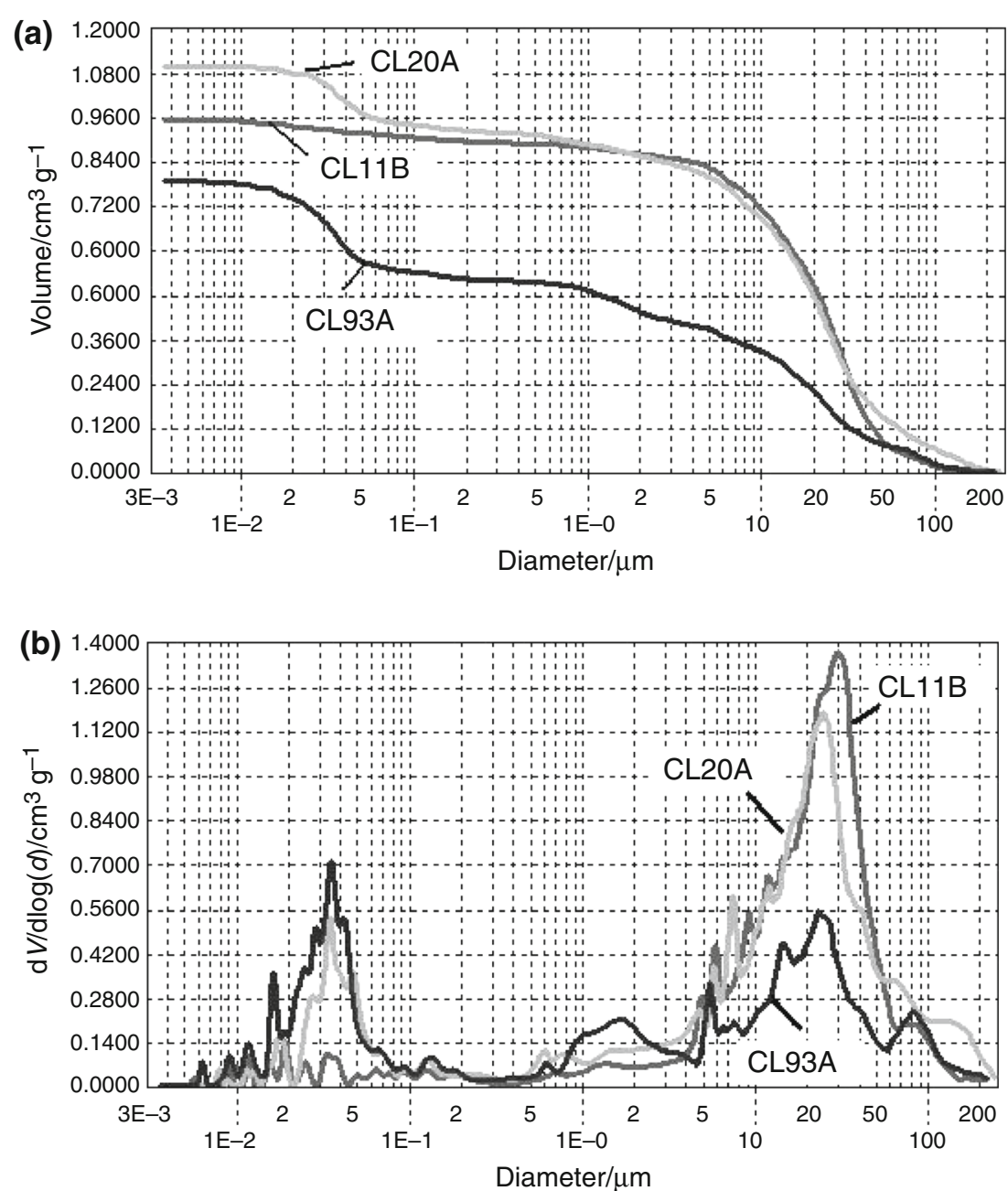

Table 4 Force required to destroy ceramized samples under compression test

\begin{tabular}{llllll}
\hline & DEL & DEL-M & CL93A & CL20A & CL11B \\
\hline$F_{\max } / \mathrm{N}$ & 1280 & 1030 & 800 & 50 & 140 \\
\hline
\end{tabular}

The strongest ceramic phase was obtained from the composite filled with unmodified montmorillonite (DEL). The composite containing montmorillonite modified in the laboratory treatment by short quaternary ammonium cations (DEL-M) has slightly worse mechanical properties,
Fig. 13 SEM pictures of crosssection of ceramized DEL composite samples micromorphology
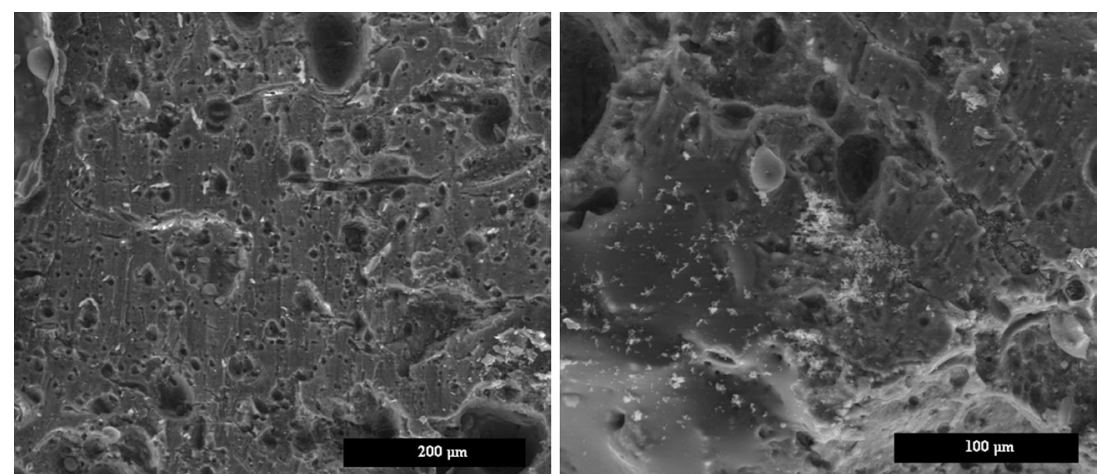
Fig. 14 SEM pictures of crosssection of ceramized DEL-M composite samples micromorphology
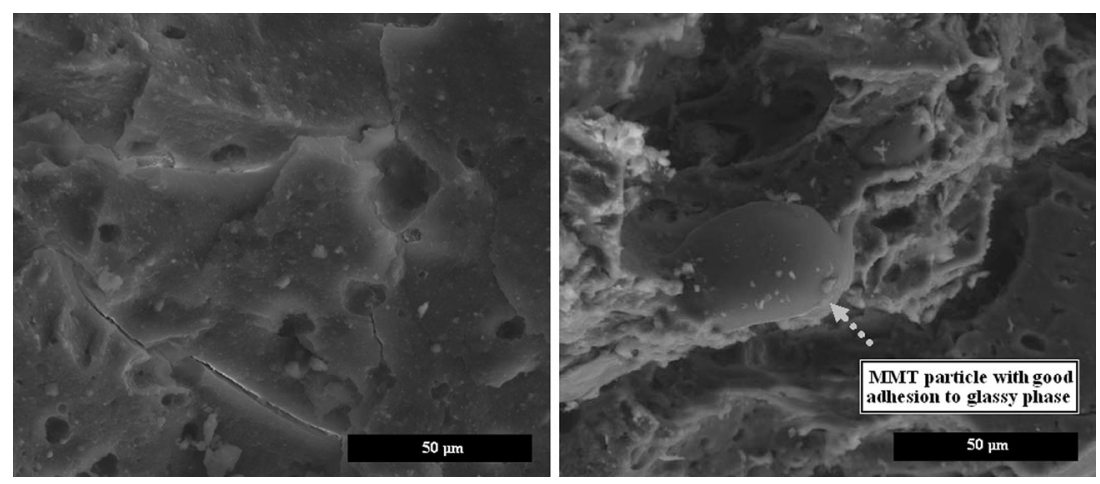

Fig. 15 SEM pictures of crosssection of ceramized CL93A composite samples micromorphology
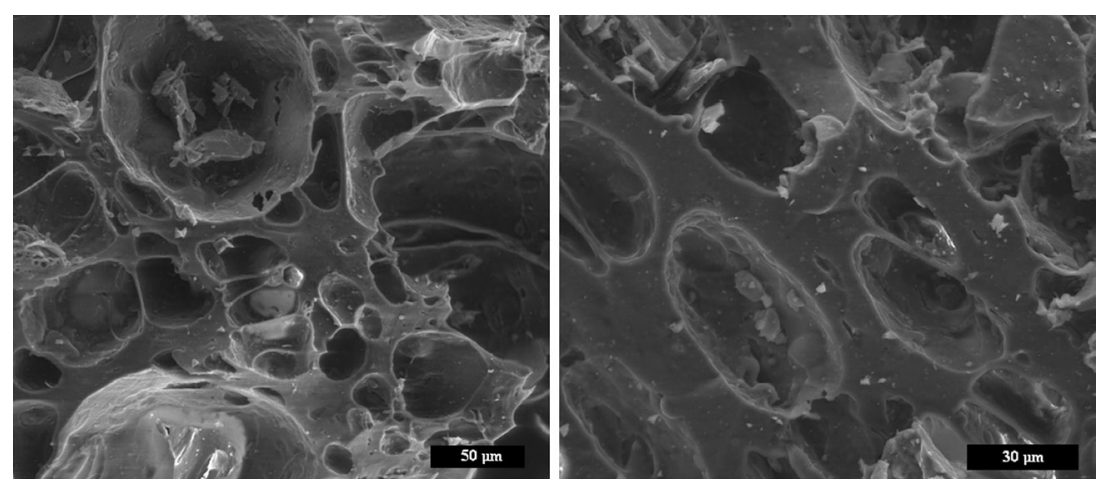

Fig. 16 SEM pictures of crosssection of ceramized CL20A composite samples micromorphology
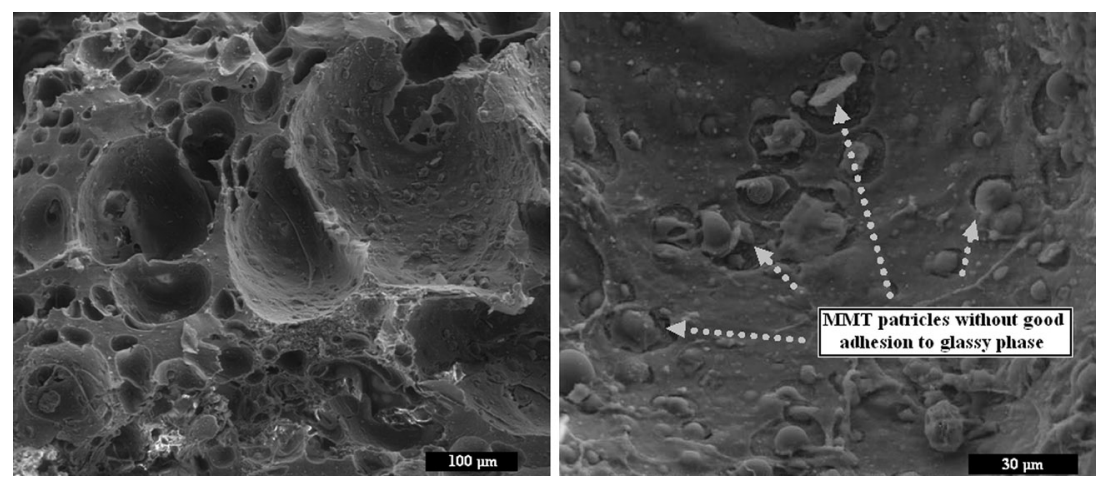

but still the value of force required to destroy it was over $1,000 \mathrm{~N}$.

Composites filled with commercially available organofilized montmorillonites have worse mechanical properties than DEL and DEL-M samples. Only the sample containing filler modified with tertiary ammonium cation (CL93A) presents quite good strength (800 N). CL11B and especially CL20A composites create very weak ceramic phases during thermal ceramization process. These results correspond well with porosimetry data, which shows that CL93A sample creates cellular structure with lower amount of voids, especially micro-sized, which could lower mechanical strength of material, than CL11B and CL20A composites.

Scanning electron microscopy pictures of the ceramized samples studied were used to complete the microstructural analysis of the composites (Figs. 13-17).
SEM pictures of ceramized composites show huge differences between morphology of samples containing commercial organofilized montmorillonites of Cloisite family (CL93A, CL20A and CL11B) and unmodified MMT (DEL) and montmorillonite organofilized in our laboratory (DEL-M). In the first case, a large number of big pores are present (5-100 $\mu \mathrm{m}$ diameter) (Figs. 15-17), which corresponds well with the porosimetry data. This kind of ceramic structure seems to be rather weak from mechanical point of view, especially when adhesion between continuous glass phase based on the fluxing agent and filler particles is quite low, like in the case of CL20A sample (Fig. 16-right).

Different kind of morphology type is observed for ceramized samples filled with unmodified montmorillonite (DEL) and MMT organofilized in the laboratory (DEL-M) 
Fig. 17 SEM pictures of crosssection of ceramized CL11B composite samples micromorphology
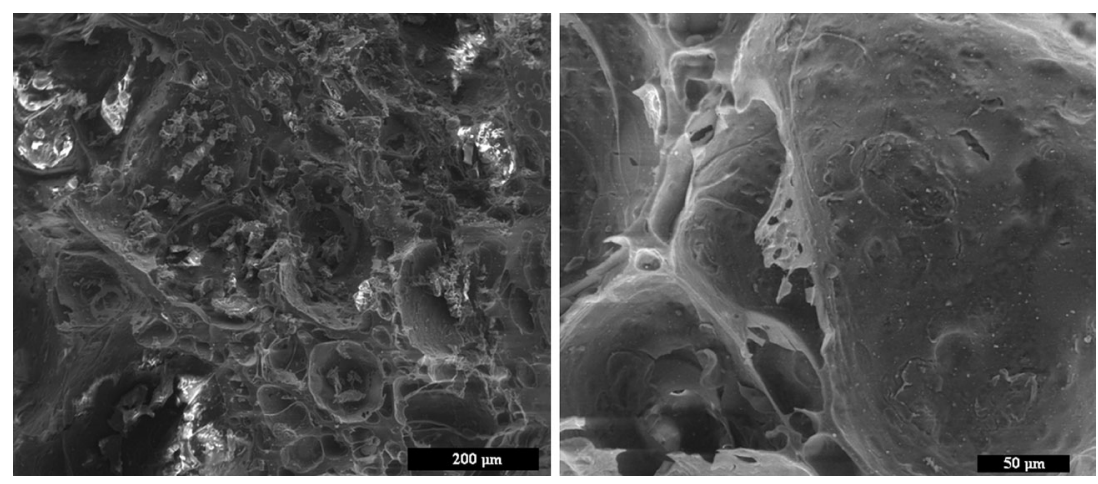

Fig. 18 Hoffman elimination reaction of montmorillonite modified using methyltributylammonium cations

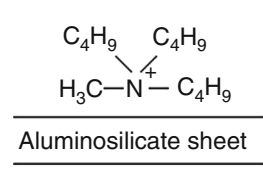

Volatiles promoting nano-porous structure $\Delta$

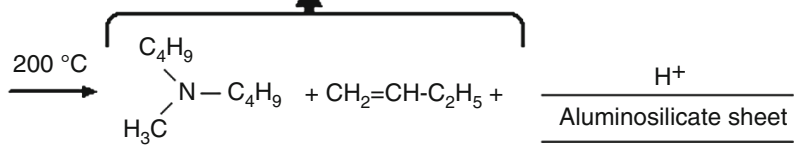

(Figs. 13, 14). In this case, large-pore content is low, which makes overall ceramic structure compact, with good adhesion between filler particles and glass phase created by a fluxing agent (Fig. 14-right).

\section{Conclusions}

Unmodified montmorillonite (Dellite HPS) contains very high amount of water. Commercially available modified MMT can contain even over 25 mass \% of organofilizer, preventing the material from water absorption.

Mechanical properties of the composites studied are closely connected to the polar component of surface energy of the filler. Composites filled with two modified powders of the highest polarity (DEL-M and CL93A) are the strongest and less elastic among the materials studied.

Flammability of all composites studies is very low. Their oxygen index value exceeds $37.5 \%$. Thermal stability is the highest for composites filled with unmodified montmorillonite (DEL) and montmorillonite modified with ammonium salt of short organic chains (DEL-M). Presence of filler modified with ammonium salt containing phenyl groups leads to the creation of relatively high amount of residue after thermal degradation of the composite.

Modification of MMT surface by methyltributylammonium cations results in the formation of nano-pores during ceramization of sample filled with this powder. This kind of structure can strongly increase the thermal insulation properties of ceramic phase without deteriorating its mechanical strength. Also, the samples filled with Cloisite 93A and Cloisite 20A create some amount of nano-pores. Probably, organic chains present in modifier molecules create volatile products during the thermal decomposition according to Hoffman beta-elimination reaction (Fig. 18), which leads to nano-porous structure. In the case of Cloisite $11 \mathrm{~B}$, aromatic ring in ammonium cation cannot create volatiles being able to produce such a structure.

Adhesion between montmorillonite filler particles and glassy phase created by fluxing agent activity depends on the type of quaternary or tertiary ammonium organofilizer. Probably, change to acidic character of MMT surface after thermal treatment affects strongly its properties.

The composite filled with laboratory-modified montmorillonite presents the best properties after ceramization. Despite slightly lower mechanical strength than composite filled with unmodified MMT, other properties were improved. Ammonium salt of short organic chains is probably the best choice in terms of mineral fillers surface modification to be applied in the silicone rubber-based composite. This time, the amount of coupling agent applied can be lower than the amount of cations in commercially available modified MMT.

Acknowledgements This work was supported by the EU Integrity Fund, Project POIG 01.03.01-00-067/08-00. Sincere thanks to Monika Kuligowska-Zarychta for providing language help.

Open Access This article is distributed under the terms of the Creative Commons Attribution License which permits any use, distribution, and reproduction in any medium, provided the original author(s) and the source are credited. 


\section{References}

1. Marosi G, Márton A, Anna P, Bertalan G, Marosföi B, Szép A. Ceramic precursor in flame retardant systems. Polym Degr Stab. 2002;77:259-65.

2. Mansouri J, Wood CA, Roberts K, Cheng YB, Burford RP. Investigation of the ceramifying process of modified siliconesilicate compositions. J Mater Sci. 2007;42:6046-55.

3. Hanu LG, Simon GP, Mansouri J, Burford RP, Cheng YB. Development of polymer-ceramic composites for improved fire resistance. J Mater Process Technol. 2004;153-154:401-7.

4. Bieliński DM, Anyszka R, Pędzich Z, Dul J. Ceramizable silicone rubber-based composites. Int $\mathrm{J}$ Adv Mater Manuf Charact. 2012;1:17-22.

5. Hanu LG, Simon GP, Cheng YB. Thermal stability and flammability of silicone polymer composites. Polym Degr Stab. 2006;91:1373-9.

6. Pędzich Z, Bukanska A, Bieliński DM, Anyszka R, Dul J, Parys G. Microstructure evolution of silicone rubber-based composites during ceramization at different conditions. Int J Adv Mater Manuf Charact. 2012;1:29-35.

7. Pędzich Z, Bieliński DM. Microstructure of silicone composites after ceramization. Composites. 2010;10:249-54.

8. Dul J, Parys G, Pędzich Z, Bieliński DM, Anyszka R. Mechanical properties of silicone-based composites destined for wire covers. Int J Adv Mater Manuf Charact. 2012;1:23-8.

9. Hamdani S, Longuet C, Perrin D, Lopez-Cuesta J-M, Ganachaud F. Flame retardancy of silicone-based materials. Polym Degr Stab. 2009;94:465-95.

10. Morgan AB, Chu LL, Harris JD. A flammability performance comparison between synthetic and natural clays in polystyrene nanocomposites. Fire Mater. 2005;29:213-29.

11. Mansouri J, Burford RP, Cheng YB, Hanu L. Formation of strong ceramified ash from silicone-based composites. J Mater Sci. 2005;40:5741-9.

12. Mansouri J, Burford RP, Cheng YB. Pyrolysis behaviour of silicone-based ceramifying composites. Mater Sci Eng, A. 2006;425:7-14.

13. Hanu LG, Simon GP, Cheng YB. Preferential orientation of muscovite in ceramifiable silicone composites. Mater Sci Eng, A. 2005;398:180-7.

14. Xiong Y, Shen Q, Chen F, Luo G, Yu K, Zhang L. High strength retention and dimensional stability of silicone/alumina composite panel under fire. Fire Mater. 2012;36:254-63.
15. Zhang J, Bai M, Wang Y, Xiao F. Featured structures of fire residue of high-impact polystyrene/organically modified montmorillonite nanocomposites during burning. Fire Mater. 2012;36:661-70.

16. Rybiński P, Janowska G, Kucharska-Jastrząbek A, Pająk A, Wójcik I, Wesołek D, Bujnowicz K. Flammability of vulcanizates of diene rubbers. J Therm Anal Calorim. 2012;107:1219-24.

17. Rybiński P, Janowska G, Jóźwiak M, Pająk A. Thermal properties and flammability of nanocomposites based on diene rubbers and naturally occurring and activated halloysite nanotubes. J Therm Anal Calorim. 2012;107:1243-9.

18. Pająk A, Janowska G, Czajkowski W, Kucharska-Jastrząbek A. Effect of the phthalocyanine pigments on the properties of butadiene rubber. Przem Chem. 2010;89:1189-92.

19. Rybiński P, Janowska G, Jóźwiak M, Pająk A. Thermal stability and flammability of butadiene-styrene rubber nanocomposites. J Therm Anal Calorim. 2012;109:561-71.

20. Janowska G, Kucharska-Jastrząbek A, Rzymski WM, Pająk A. Thermal properties nad combustibility of cross-linked XNBR/ CSM blends. J Therm Anal Calorim. 2012;109:1481-6.

21. Carlos J, Hilado PE. An overview of the fire behavior of polymers. Fire Technol. 1973;9:198-208.

22. Wang Y, Zhang F, Chen X, Jin Y, Zhang J. Burning and dripping behaviors of polymers under the UL94 vertical burning test conditions. Fire Mater. 2010;34:203-15.

23. Wilkie CA, Morgan AB. Fire retardancy of polymeric materials. 2nd ed. Boca Raton: Taylor \& Francis; 2010.

24. Camino G, Lomakin SM, Lazzari M. Polydimethylsiloxane thermal degradation Part 1. Kinetic aspects. Polymer. 2001;42:2395-409.

25. Camino G, Lomakin SM, Lageard M. Thermal polydimethylsiloxane degradation. Part 2. The degradation mechanisms. Polym 2002; 43: 2011-2015.

26. Porter D, Metcalfe E, Thomas MJK. Nanocomposite fire retardants-a review. Fire Mater. 2000;24:45-52.

27. Xie W, Gao Z, Pan WP, Hunter D, Singh A, Vaia R. Thermal degradation chemistry of alkyl quaternary ammonium montmorillonite. Chem Mater. 2001;13:2979-90.

28. Zanetti M, Camino G, Thomann R, Mulhaupt R. Synthesis and thermal behaviour of layered silicate-EVA nanocomposites. Polym. 2001;42:4501-7.

29. Zanetti M, Camino G, Mulhaupt R. Combustion behaviour of EVA/fluorohectorite nanocomposites. Polym Degr Stab. 2001;74:413-7. 